
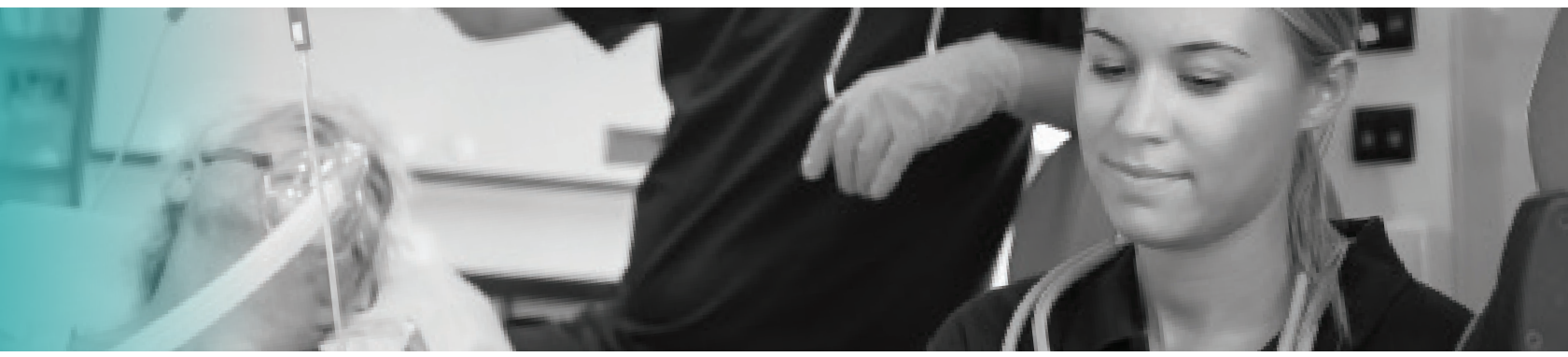

Volume 14 | Issue 3 | Article 3
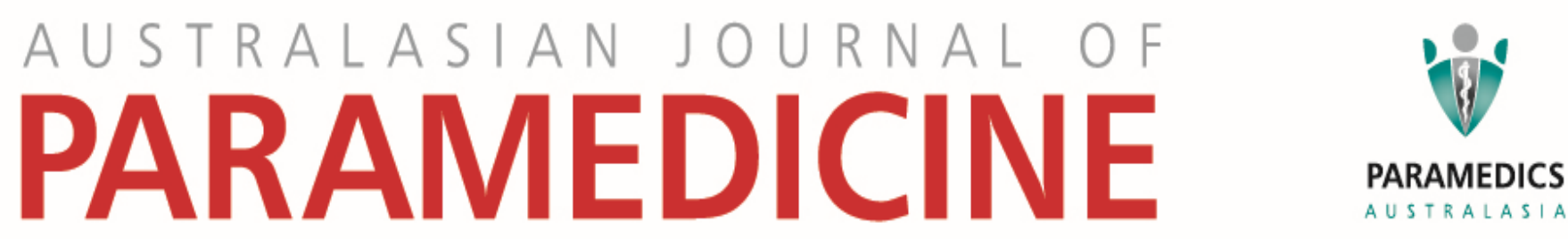

Four dimensions of paramedic practice in Canada: Defining and describing the profession

Ron R Bowles

Justice Institute of British Columbia, Canada

Catherina van Beek

Justice Institute of British Columbia, Canada

Gregory S Anderson

Justice Institute of British Columbia, Canada 


\title{
Research
}

\section{Four dimensions of paramedic practice in Canada: Defining and describing the profession}

\author{
Ron R Bowles PhD, is Associate Dean, Centre for Applied Research ${ }^{1 ;}$ Catherina van Beek RN, BSN, MHA, CHE, is \\ Research Strategist ${ }^{1}$; Gregory S Anderson PhD, is Dean, Office of Applied Research and Graduate Studies ${ }^{1}$
}

\section{Affiliations:}

${ }^{1}$ Justice Institute of British Columbia, Canada

\section{Abstract}

\section{Introduction}

This article presents a framework for describing four dimensions of paramedic practice: Practitioners, Practice Setting, Care and Patient Disposition. The framework emerged from a qualitative study conducted to identify potential research directions and opportunities to advance paramedicine and paramedic education at Justice Institute of British Columbia in Canada.

\section{Methods}

Researchers conducted semi-structured interviews with 17 stakeholders in Canadian paramedicine to explore the current state and emerging expectations of paramedic practice and paramedic education.

\section{Results}

The study found no consensus, and little agreement, on what term or terms best describe the profession. Participants agreed that the core of paramedic practice involves an advanced medical provider responding by ambulance to the patient's side in an emergency to assess and treat urgent medical and traumatic conditions, then transport the patient to further medical care - most often an emergency physician at an emergency department. However, participants also described paramedics as healthcare providers who are increasingly taking on varied operational roles to improve patient care and address gaps in an evolving and stressed healthcare system. Four dimensions emerged for describing key characteristics of paramedic practice: the Practitioners, Practice Settings, Care and Patient Disposition.

\section{Discussion}

The framework described in this article may be useful for examining and better understanding both traditional and evolving paramedic roles. This, in turn, informs the efforts of paramedic educators, regulators, employers, and professional associations to support practitioners in the field. The article uses the framework to contrast two distinctly different community paramedic programs.

\footnotetext{
Keywords:

paramedics; paramedic practice; paramedicine; EMS; profession; discipline boundaries
}

Corresponding Author: Ron Bowles, rbowles@jibc.ca 


\section{Introduction}

In 1971, the American Academy of Orthopedic Surgeons published the first edition of Emergency Care and Transportation of the Sick and Injured (1) as a national text for emergency medical care. The title of this text serves as an apt description of the role of ambulance services at that time. By 2006, these services had evolved into complex emergency medical systems (EMS) and a white paper published by the Paramedic Chiefs of Canada (PCC) (2) posed a future vision for EMS in Canada as 'a community-based mobile healthcare service' (p. 18).

Healthcare in Canada is regulated at the provincial level $(3,4)$ and the professional boundaries of paramedic practice are set through provincial legislation, such as the British Columbia Emergency Health Services Act (5). This legislation typically defines who paramedics are, their mandate, where they may practice (both geographically and practice setting), and establishes processes for licensure (in provinces such as British Columbia) or self-regulation in other provinces (such as New Brunswick) (6). In British Columbia, the actual scope of practice is outlined in the Emergency Medical Assistants Regulations (7), which lists the practices, procedures and medications that may be used by paramedics at various certification levels. Specific practices in the field are established by ambulance operators through policy, procedures, protocols and/or clinical practice guidelines. Actual practice 'on the street' is influenced by a number of factors that may include the paramedic's background, training and experience, operational role (eg. emergency response ambulance, airevac, special teams), the call distribution within the responding area and local practice.

The profession - variously called EMS, paramedicine and paramedic practice - is rapidly evolving. In addition to traditional roles in responding to, treating and transporting the sick and injured, paramedics now participate in specialised teams (8-10), practice at fixed locations ranging from mass gatherings (11) to remote industrial sites (12), within hospitals $(13,14)$, long term care $(15)$ and community settings (1618). While providing urgent care in emergency situations, paramedics increasingly provide non-urgent care and monitoring $(17,18)$, primary care $(19,20)$, preventive care and health education $(19,21,22)$. Traditionally, paramedics transported patients to medical care, usually the closest emergency department. However, patient disposition options now include programs for critical care bypass of multiple trauma, acute cardiac and stroke patients (23-32), treat and release $(22,15,17,33)$ and referral to other health and social service providers $(15,18,33)$.

The evolution of the profession raises questions about how to define and describe paramedic practice, and what its boundaries or limits are. For example, how does an 'emergency health service' differ from an 'ambulance service'? Does providing onsite management and monitoring of minor injuries and illnesses at a remote industrial camp fit within the scope of the practice and licensure of a paramedic? Does paramedicine include high acuity interfacility transport by interprofessional healthcare teams? Paramedics may be members of police tactical response teams; but is a police officer on the same team with emergency medical training also practicing paramedicine? How are these varying roles, practice settings, and types of care incorporated within professional documents such as occupational profiles and standards of practice? How do educational programs approach and support these changes?

This article addresses questions such as these through the lens of a research study at Justice Institute of British Columbia in Canada (JIBC). The primary research goal was to identify potential directions and opportunities for JIBC research efforts to contribute to and advance paramedic practice and education in Canada. The changing expectations, operational roles and scope of practice in paramedicine have a direct impact on both educational content and educational practice. Thus, the study explored current conceptions of the terms, roles, boundaries and future directions of Canadian paramedic practice, and sought to identify key issues and problems facing stakeholders in Canadian paramedic education.

\section{Methods}

The study employed semi-structured interviews of key informants from selected stakeholder groups involved in paramedicine in Canada generally, and British Columbia in particular. Key informant interviews focused on identifying trends, issues and challenges with an emphasis on educational aspects of paramedic practice. An inductive thematic analysis was conducted following the general procedures of grounded theory $(34,35)$. Results of this analysis were interpreted through the lens of identifying areas of research that would inform paramedic practice and education within Canada.

\section{Participants}

Interview participants were recruited using purposeful and convenience strategies, seeking key informants from diverse stakeholder groups that could provide insight on the central questions of this research (36). Selection characteristics included membership in key stakeholder organisations, operational role and regional/geographic focus. Potential organisations and key individuals were identified by JIBC's Health Sciences Division leadership group. Potential participants were initially contacted by email with telephone follow up. Participants unavailable or unwilling to participate were asked to identify other potential candidates with similar characteristics. 


\section{Procedures}

Two researchers (RB and CVB) conducted 17 individual hour-long semi-structured interviews, consisting of five openended questions, each with prompting questions (see Table 1). Participants were encouraged to use the questions as starting points, not as boundaries. The researchers allowed the conversations to emerge organically. All interviews were audio-recorded then transcribed verbatim by both researchers (RB and CVB) using Transana (37), with each researcher reviewing the other's work against the audio recordings to ensure accuracy. Researchers also took field notes in the interviews. Coding notes, memos, and interim writings on emergent themes gathered throughout the study became additional data.

\section{Table 1. Semi-structured interview questions}

\section{Can you describe your background in EMS?}

- When did you enter the service, where, and in what role?

- What has your career trajectory been?

- What aspects of EMS are you involved in and at what levels: operational role, organisational role, 'systems' role (local, provincial, national, international)?

2. How would you describe the world of EMS?

- What is the best term to use to describe the field? Why?

- What is the primary role or function of EMS? What should it NOT be doing? Why?

- What's in and what's out? Where are the boundaries of EMS? (eg. community care, primary healthcare, industry, in-hospital)

- Where do you see EMS going in the next 5 years?

3. How could research help you deal with issues and problems in EMS?

- What types of issues and problems do you deal with?

- How might research help you with those?

- What would you like to know that would help you solve problems, do things better, advance the profession?

- What are the issues and problems that we can't even tackle right now?

4. What are the gaps and holes in the EMS knowledge base?

- What do we not know that we probably should?

- What information would you really like to have that you don't have right now? (eg. \# calls done across Canada on a daily basis; how many paramedics are in Canada; how long the 'average' paramedic stays in the service)

- Note that this can be more than clinical: can prompt for political, operational, education, etc.

5. What are the puzzles and problems - what are you 'curious' about? What would you like to know?

- Meant as an open-ended question.

- Can use framework (political, operational, education) to prompt for areas that have not been addressed above.

- Focus on curiosity and needs - how can research make life better, solve problems.

\section{Data analysis}

Analysis and interpretation employed inductive thematic analysis, consistent with procedures of grounded theory as described by Chamaz (34) and Corbin and Strauss (35). The researchers engaged in an ongoing cycle of interview, transcription, analysis and discussion, allowing emergent findings to help inform and focus subsequent data collection. Initial analysis involved listening to the audio recordings while concurrently reviewing the transcripts, followed by line-by-line open coding. Core terms describing paramedicine were extracted from the transcripts then mapped to look for relationships, similarities and differences, with particular attention to developing an understanding of how terms describing paramedicine overlapped, informed and contradicted each other. Data elements were coded using a mix of in vivo and emergent codes. Conceptually similar codes were brought together into coding categories. These categories were then analysed axially and in relationship to the main research questions to explore participants' descriptions and understandings of paramedic practice, the current and future roles of paramedicine, and the discipline's perceived boundaries. 
Chamaz (34) noted the purpose of grounded theory as the development of middle-range theories that allow for conceptualisation of key issues in a manner that allows more complex analysis of the data. Chamaz (34) described the process of looking at variation within categories and for relationships between categories with the goal of theory development. She identified four characteristics of developing theory: a description, an empirical generalisation, relationships between categories, and an abstract understanding of relationships between the concepts in the theory. This process informed the development of the 'Four Dimensions of Paramedic Practice' discussed below.

\section{Ethics}

The study received ethical approval and oversight from the Justice Institute of British Columbia Research Ethics Board. Note that the initial study design employed semi-structured interviews, allowing for adaptation of the interview questions to explore emergent findings. The study received no external funding. Both researchers conducted the study in their roles at JIBC.

\section{Results}

\section{Participant characteristics}

Seventeen participants engaged in semi-structured interviews. Almost half $(n=7)$ were current or former paramedics, with the remaining participants from nursing, medicine, and other health professions. Many held primary roles within their operational organisation (eg. a provincial regulator) while also holding a leadership role within a provincial or national organisation. Several participants held both operational/clinical roles and academic appointments. Seven participants held primarily operational or clinical positions, with five holding leadership positions within provincial agencies or organisations. Five participants also held leadership positions within national organisations such as the Paramedic Association of Canada, Paramedic Chiefs of Canada, Canadian Organization of Paramedic Regulators, and the Society for Prehospital Educators in Canada. While the majority of participants were from British Columbia $(n=11)$, participants were recruited from five provinces representing British Columbia, the Prairies, Central Canada and Atlantic Canada. Note that there were no participants from Quebec or the northern territories.

\section{Findings}

Several of the questions in this study explored how participants understood and described paramedic practice for example, what operational roles or functions paramedics assume, what distinguishes paramedicine from other health disciplines, and what participants perceived as the boundaries of the profession. Participants' general descriptions of paramedicine coalesced around two holistic conceptions: a 'traditional' view of paramedicine as ambulance-based emergency response, treatment and transport and an emerging view of paramedicine as a healthcare discipline that is evolving to support a stressed healthcare system. Multiple codes emerged as describing different aspects of paramedicine and these, in turn, led to the development of four conceptual dimensions. Further analysis of the codes within each dimension in relationship to the two emerging holistic conceptions led to the identification and organisation of elements within each dimension. What emerged was a framework for describing key dimensions and attributes of paramedic practice. The two conceptions of paramedicine and the resulting framework are described in the following sections.

\section{What's in a name? Terms describing the discipline} There was no consensus (and little agreement) on what term or terms best describe the profession. The discussion on this topic was wide ranging, and participants tended to spend more time explaining why they did not like specific terms than in justifying the terms they preferred. Three general sets of terms emerged (see Table 2). Terms such as 'EMS' (emergency medical services) and 'EHS' (emergency health services) were seen as emphasising the traditional emergency aspect of ground ambulance-based services and not acknowledging emerging functions of paramedics in less urgent, continuing and preventive care. A second set of terms focused on the practitioners themselves such as 'paramedicine' or 'paramedic practice'. Some participants noted that these were 'boundary' terms that excluded other types of health providers and emergency responders from the profession. Finally, terms such as 'pre-hospital' and 'out-of-hospital care' were situated in the place of practice but were seen as not inclusive of emerging or non-traditional uses of paramedics in broader health and community settings. The tension between these terms highlights conflicting conceptions or dimensions that may define the profession, including who the practitioners are (paramedics and other health providers), where they practise (ambulance, community- or location-based and/or in-hospital), and what their role is (emergency care, definitive care, preventive care).

The researchers propose two terms for describing paramedic practice in the remainder of this article. 'Paramedicine' is used as an umbrella term for paramedic practice in its broadest sense, regardless of who the practitioners are, their practice setting, the type of care provided and patient disposition. The term 'EMS' is used to refer to traditional paramedic staffed land- and air-based ambulance services or systems. In this conception, EMS can be thought of as one of the practice settings that makes up the broader discipline or profession of paramedicine. 
Table 2. Terms used to describe the discipline

\begin{tabular}{|c|c|c|c|}
\hline 'Emergency' terms & Practitioner terms & $\begin{array}{c}\text { Context of practice } \\
\text { terms }\end{array}$ & Other terms \\
\hline $\begin{array}{l}\text { - EMS } \\
\text { - Emergency medical services } \\
\text { - EHS } \\
\text { - Emergency health services } \\
\text { - Health services }\end{array}$ & $\begin{array}{l}\text { - Paramedicine } \\
\text { - Paramedic care } \\
\text { - Paramedic practice } \\
\text { - Paramedics } \\
\text { - Paramedic service }\end{array}$ & $\begin{array}{l}\text { - Pre-hospital } \\
\text { - Pre-hospital care } \\
\text { - Pre-hospital medicine } \\
\text { - Out-of-hospital } \\
\text { - Ambulance } \\
\text { - Ambulance medicine }\end{array}$ & $\begin{array}{l}\text { - First responders } \\
\text { - Bastard child of medicine }\end{array}$ \\
\hline
\end{tabular}

\section{The core of paramedicine}

The challenge of naming the profession extended to participants' efforts to define its central role or purpose. Participants identified two conceptions of paramedicine one based in the historical roots of EMS and the other in the expanding role of paramedicine in an evolving healthcare system. All participants saw the traditional view of EMS as the core role of paramedicine, but differed in the degree to which they saw evolving roles as 'within the discipline'.

At its core, paramedicine involves a practitioner trained in advanced medical care driving an ambulance to the patient's side in an emergency to assess and treat urgent medical conditions and traumatic injuries, then transport the patient to further medical care in a hospital - most often to an emergency physician at an emergency department. All participants agreed with this conception of EMS.

'I think it's essentially the system responsible for providing timely access to a healthcare professional when an acute emergency arises... and to make a decision about whether or not care can be provided in that setting or in an alternate setting or if transportation to an acute care facility is required'. (Participant 103)

'I think the premier role should be rapid intervention in critical situations that are time sensitive where the interval from event to hospital is too long for satisfactory outcomes a high percentage of the time'. (Participant 106)

However, participants differed in the degree to which they saw emerging roles as part of paramedicine. Contrasting views situated paramedics as healthcare providers who are increasingly taking on varied roles to improve patient care and address gaps in a stressed and evolving healthcare system.

'We're not just emergency care. We're certainly well beyond that with some of the systems that exist that allow for things like treat and release and for community based practice'. (Participant 104)

'It's an extension of any health authority or government health service, whether it's the state, whether it's federal, provincial... I think that... EMS is one of the initial phases of delivery healthcare'. (Participant 109)

'EMS has to start looking at themselves as part of the first layer of healthcare'. (Participant 108)

'Really I think in the broadest of terms I think we are the safety net for the healthcare system'. (Participant 106)

The participants' comments mirror discussion in the literature that contrasts EMS as an emergency service and paramedicine as an evolving healthcare profession (2,38-43). However, the participants' language and examples did not frame these as 'either/or' conceptions; rather, all participants saw the traditional definition as the core of EMS, but differed on the degree to which they saw aspects of changing practice as 'in' or 'out' of their conceptions of paramedic practice.

\section{Dimensions describing paramedic practice}

Participants provided a wealth of terms, phrases and concepts for defining and describing aspects of paramedic practice. These included terms used to name the discipline, descriptions of the purpose or role of paramedicine, examples of existing and emerging practice they considered within or outside the bounds of the profession, and features that distinguished paramedicine from other health disciplines.

Participants identified a wide range of emerging roles and capabilities for paramedics:

- Community paramedic

- Expanded practice

- Moving towards diploma/degree

- Code response (managing cardiac arrest) and urgent response within the hospital

- Community or even in-hospital care

- Access to care; providing community care and preventative healthcare

- Trying to lessen or eliminate where possible people that are chronically sick from having to access the healthcare system in its traditional form

- Specialty teams such as tactical response, mass gatherings, HAZMAT. 
Table 3. Dimensions of paramedic practice

\begin{tabular}{|c|c|c|c|}
\hline Practitioner & Practice settings & Care & Patient disposition \\
\hline $\begin{array}{l}\text { Paramedic: } \\
\text { - Critical care } \\
\text { - Advanced care } \\
\text { - Primary care } \\
\text { Specialty Responders: } \\
\text { - Tactical EMS } \\
\text { - CBRNE/HAZMAT } \\
\text { - Special events } \\
\text { - Industrial } \\
\text { First responders: } \\
\text { - Emergency medical responders } \\
\text { - Fire/other first responder } \\
\text { Community resources: } \\
\text { - Lifeguard } \\
\text { - Search and rescue tech } \\
\text { - Dual role: EMS/fire } \\
\text { Healthcare providers: } \\
\text { - Nurse, nurse practitioner } \\
\text { - Physician, physician assistant } \\
\text { - Other health disciplines }\end{array}$ & $\begin{array}{l}\text { Uncontrolled: } \\
\text { - At the patient's side } \\
\text { - Out-of-hospital (eg. home } \\
\text { visit) } \\
\text { Location-based: } \\
\text { - Events (eg. sports, con- } \\
\text { certs, mass gatherings) } \\
\text { - Industrial sites } \\
\text { - In community (eg. 'store } \\
\text { front') } \\
\text { Community-based: } \\
\text { - Home visits } \\
\text { - BP/diabetes clinics } \\
\text { Facility-based: } \\
\text { - In-hospital (eg. ED, triage, } \\
\text { code team) } \\
\text { - In-facility (eg. extended } \\
\text { care) } \\
\text { - Rural ED (eg. night cover- } \\
\text { age) }\end{array}$ & $\begin{array}{l}\text { Emergency: } \\
\text { - Emergency responses } \\
\text { - Urgent responses } \\
\text { - Non-emergency/ routine } \\
\text { responses } \\
\text { - In-hospital code/cardiac } \\
\text { arrest responses } \\
\text { Urgent/ongoing care: } \\
\text { - Interfacility monitoring and } \\
\text { intervention } \\
\text { - Triage or monitor (in-hospi- } \\
\text { tal/ED) } \\
\text { Definitive: } \\
\text { - Treat and bypass (eg. } \\
\text { trauma, stroke, STEMI) } \\
\text { - Treat and release (eg. } \\
\text { diabetic) } \\
\text { - Treat and refer (eg. BP } \\
\text { clinic, home visit) } \\
\text { - Interprofessional/team } \\
\text { based care (eg. IPP team } \\
\text { in ED; paramedic/nurse } \\
\text { staffing rural ED) } \\
\text { Primary and preventative } \\
\text { healthcare: } \\
\text { - Health surveillance } \\
\text { - Primary healthcare moni- } \\
\text { toring } \\
\text { - Public health education }\end{array}$ & $\begin{array}{l}\text { Transport to care: } \\
\text { - Ambulance calls } \\
\text { - Airevac } \\
\text { Transport between care: } \\
\text { - Interfacility transfers } \\
\text { - Critical care transfers } \\
\text { Care in place (no transport): } \\
\text { - Treat and release } \\
\text { - Treat at point of care (eg. } \\
\text { in-facility, ED) } \\
\text { - Treat and refer }\end{array}$ \\
\hline
\end{tabular}

Analysis of these data led to the emergence of four conceptual categories or dimensions: who the practitioners are, where they practice, what type of care they provide, and who/where they transition care of the patient to (referred to in this article as 'patient disposition'). Further analysis of the codes within each category led to the development of a series of attributes or elements within each dimension (see Table 3).

Paramedicine is a relatively young discipline that is rapid evolving and the lack of agreement in terminology reflects the role confusion expressed by many participants. While most participants recognised that emerging roles and the changing scope of paramedic practice required different ways of describing the field, there was still a strong attachment to the concept of an advanced care paramedic in an ambulance responding to the patient's side, intervening to manage a medical or trauma-related crisis, and then transporting the patient to hospital. Thus, the final categorisation of the data was to hierarchically organise the elements in each dimension in relationship to its conceptual 'closeness' to the 'core' or traditional view of paramedicine.

\section{Four dimensions of paramedic practice}

Figure 1 presents a graphic representation of four dimensions emanating from a core concept of paramedic practice. The elements in each dimension are ordered from those most closely associated with the core definition to those that have the least in common or are conceptually 'farthest' from traditional descriptions of paramedic practice.

There was general agreement among the participants on the elements that form the core of paramedic practice. However, changing any of the elements in that description elicited considerable disagreement on whether or not the resulting description was still within the bounds of paramedic practice. The greater the degree of change, the less agreement there was among participants. 


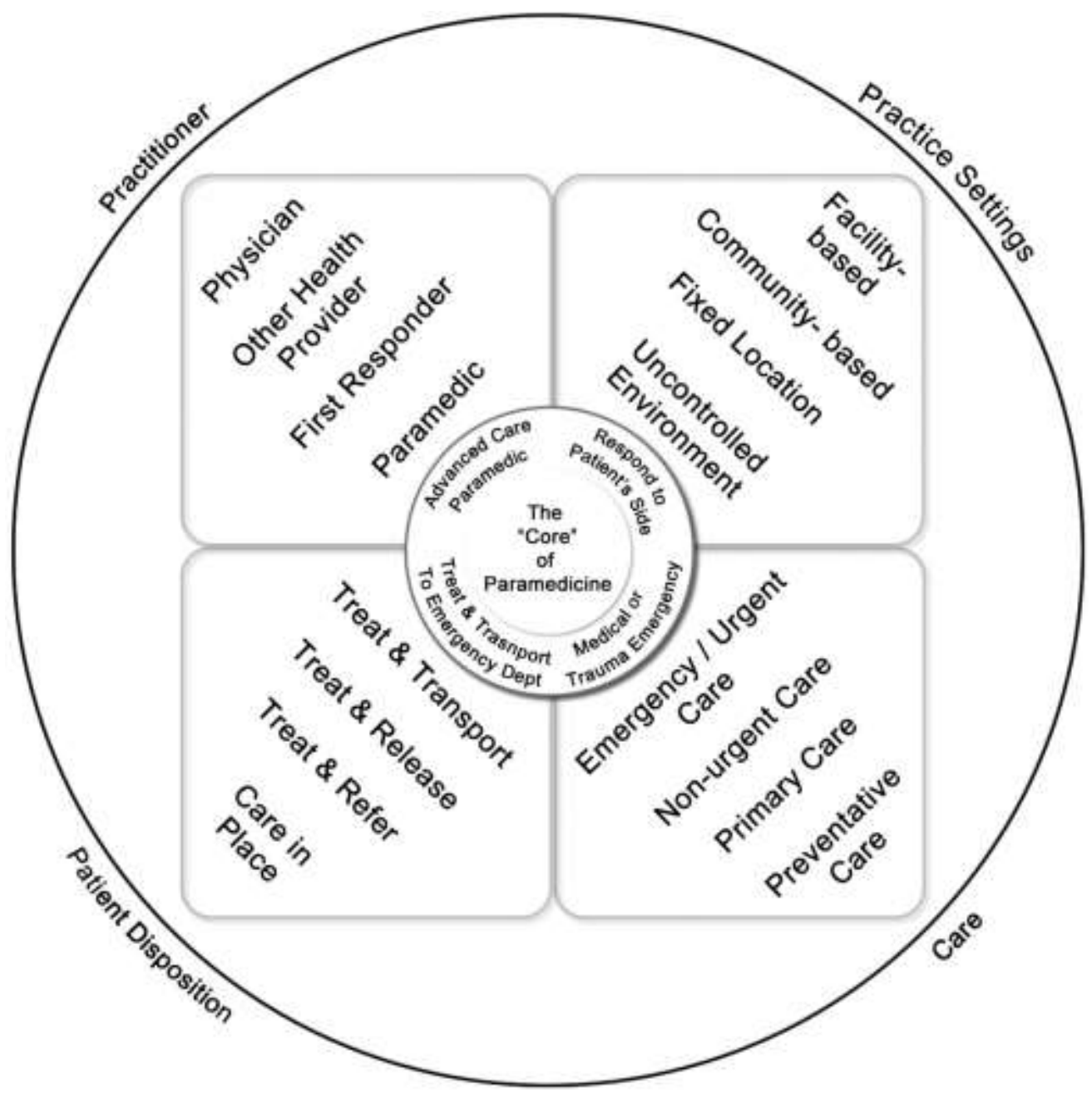

Figure 1. Four dimensions of paramedic practice

\section{Practitioners}

There was general agreement among the participants that paramedics form the core of the profession. However, there was less agreement on whether or not being a paramedic is what defines the profession. One participant saw only advanced life support providers as paramedics (in line with the traditional division between paramedics and emergency medical technicians or assistants). Most participants included critical care, advanced care and primary care paramedics (which are the current certification levels found in many Canadian provinces) as being within the profession. Several participants explicitly excluded emergency medical responders and/or other providers of emergency care (such as specialty teams, lifeguards, search and rescue technicians or industrial medics) from being part of the profession. Other participants saw membership in paramedicine much more inclusively, noting that ambulance services, and in particular high acuity transport and airevac teams in many jurisdictions - including some areas of Canada - are routinely staffed by nurses, physicians, and other healthcare providers.

\section{Practice settings}

One of the defining characteristics of ambulance-based care was described as its uncontrolled and unpredictable setting - while most healthcare requires the patient to come to a hospital or practitioner's clinic, paramedics respond to where the patient is. However, participants noted that paramedics are increasingly taking on new roles in industry, locationbased settings (eg. concerts, sporting events and other mass gatherings), and in-facility settings such as emergency departments, health clinics and extended care facilities.

There was no agreement on whether these alternate settings were within or outside the profession. Several distinguished between EMS, which included traditional land- and air-based ambulance services, and a broader view of paramedicine comprised of multiple practice settings. This conception focused on the practitioners as defining the profession (of paramedicine), with EMS, community-care, and in-facility roles all as subsets or practice settings in which paramedics could function. 


\section{Care}

All participants agreed that emergency care is core to paramedicine. Several participants limited the boundaries of paramedicine solely to emergency care, seeing nonemergency care, interfacility transport or community-based care as being non-paramedic duties. Other participants easily accepted paramedicine as including the provision of definitive care (examples included treat and release programs for diabetics or paramedics in multi-disciplinary teams in emergency departments). Several participants described paramedics performing primary healthcare monitoring and preventive care as part of providing mobile community-based health services.

\section{Transport/disposition}

Again, all participants noted that transport and transfer of care to emergency physicians in the emergency department is a core element of paramedic practice. However, most participants noted that this is a dimension whose elements are rapidly changing. Several participants mentioned treat and release programs and bypass protocols for specific categories of trauma, cardiac and stroke patients. In addition, participants described emerging and potential programs allowing paramedics to treat in place, treat and refer and monitor patients in their homes.

\section{Discussion}

The participants in this study characterised paramedic practice as transitioning from its roots as an emergency service towards a broader conception as a diverse healthcare discipline or profession. There was no common term for the discipline, nor did the participants agree upon its boundaries. There was, however, a strong consensus on paramedicine's core function as responding to the patient's side in an emergency to provide urgent care and transport to hospital. Further, there was agreement that paramedics are increasingly providing a wide range of care to patients in a growing set of practice contexts, involving alternative disposition and transfer of care. These characteristics form the four dimensions of paramedicine practice presented in this article.

This framework is useful for examining and contrasting evolving roles within paramedic practice. This, in turn, informs the efforts of paramedic educators to develop effective programs to support practitioners, regulators to explore the scope and contexts of paramedic practice, and service operators to identify and meet patient and community needs.

\section{Case study: Community paramedic programs}

Community paramedic programs are increasingly common throughout Canada and internationally $(40,44-47)$. Yet there is substantial variation among these programs, both operationally and in the education required to support them. Some programs leverage 'down-time' between calls of landbased ambulance paramedics to complete home visits and monitor 'frequent flyers' - patients who frequently attend local emergency departments $(24,27)$. Programs such as these can be mapped onto the Four Dimensions framework as illustrated in Figure 2. Other community paramedic programs create new roles and employ paramedics to set up clinics in remote locations and conduct primary healthcare monitoring and education $(15,48,49)$. Figure 3 illustrates how these types of programs can be represented using the Four Dimensions framework. The first example stays 'close' to the core of paramedic practice and practitioners. Little has changed in terms of location of practice, care, or decisions around patient disposition. In contrast, paramedics responding to remote communities employ similar skills, but make very different decisions, including monitoring health trends over time and referring patients to other health providers rather than transport to hospital. While both are 'community paramedic' programs, they have distinct differences in the 'distance' from traditional practice (and education), and require different types of educational support.

A distinguishing aspect of this model, and the descriptions of paramedic practice from which it emerged, is the focus on the overall context and outcome of practice, rather than on skills and knowledge of the practitioner. Traditional paramedic occupational descriptions, regulatory frameworks and educational models (49) have focused on differentiating types of paramedic practice by skill- and procedurebased taxonomies (eg. routes of drug administration, use of advanced or invasive procedures, types of injuries or conditions with medical directives or protocols) - features rarely mentioned by the participants in this study when describing current and future paramedic practice. Rather, the participants' discussion, and the resulting dimensions of practice framework, looked more at the capabilities and attributes required of paramedics within varying practice contexts, and in particular their ability to adapt to changing settings and new roles.

This finding has interesting implications for the development of professional documents describing practice. Occupational profiles in several health and medical disciplines, such as the CANMeds (50) and the Canadian physiotherapy profile (51), have adopted role-based descriptions that focus on the functional roles of practitioners, and the capabilities required to assume those roles (52). This, then, highlights the need for paramedic education programs to explore how foundational skills, knowledge and decision-making change when practitioners provide expanded forms of patient care involving alternative patient dispositions in varied practice settings. 


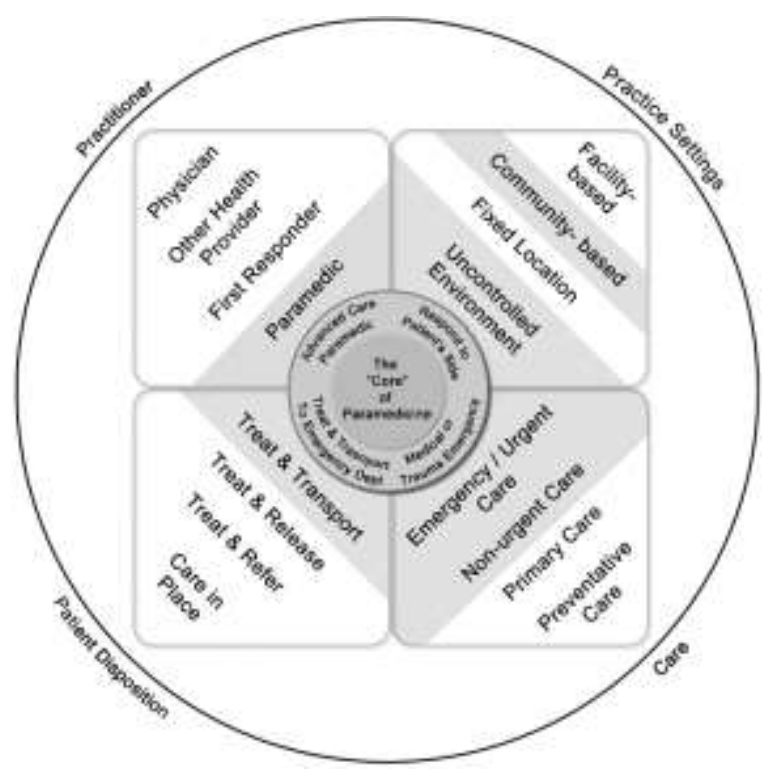

Figure 2. Land-based ambulance with home visit roles

The four dimensions presented in this article provide educational programs a framework with which to analyse and incorporate the complexity of emerging paramedic practice into learning environments such as simulations and practicum experiences.

\section{Limitations}

This study was set in the context of developing a program of research to advance practice and inform paramedic education in the Canadian, and more specifically, within the British Columbian context. While participants were selected with the goal of broad diversity in professional background, operational perspective, and geography, the data obtained in this study cannot be considered representative of all stakeholders in Canadian paramedicine. Rather, the intention of the study was to explore and better understand the range of perspectives and understanding participants had of paramedic practice, not to examine the prevalence of those views among, or between, stakeholder groups.

The emergence of the four dimensions of paramedic practice, and the ordering of elements within those domains were influenced by the backgrounds and experience of the researchers as a paramedic (RB) and a nurse (CVB), and as educators and researchers. Other researchers may have developed different categories or seen different relationships within those categories. We acknowledge these limitations

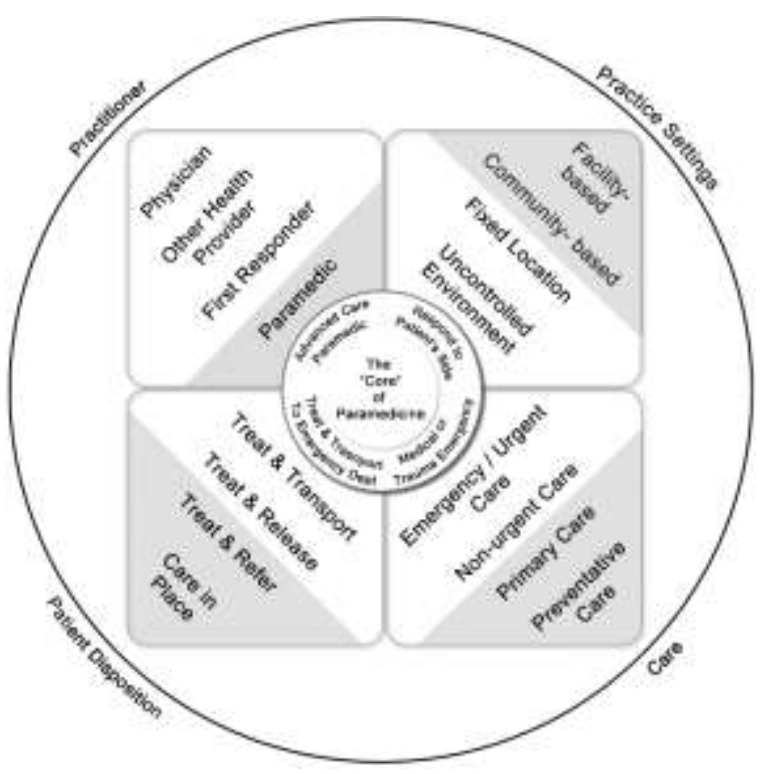

Figure 3. Paramedics stationed in rural communities with primary and preventative care roles

and offer the framework as a starting point for discussion and an invitation for further study.

\section{Conclusion}

As paramedics take on new roles they push at the 'traditional' boundaries of the profession. Paramedic educators seeking to prepare practitioners for these roles face an intriguing set of challenges. Some of these new roles bring paramedics' existing scope of practice to new environments. Other roles are opportunities for paramedics with expanded scopes of practice to provide alternative forms of care within their existing context of practice. Changes in patient disposition and treatment options radically change the types of decisions paramedics will make, and the educational foundation needed to function effectively.

The four dimensions proposed in this article provide a framework for exploring, comparing and contrasting attributes of various forms of paramedic practice. The examples provided show that different paramedic roles may share attributes along some dimensions and vary among others. Further study is required to better understand the relationships between these dimensions, and to explore how different 'maps' may relate to the underlying skills, knowledge, and decision-making, and perhaps more importantly, their integration and adaptation within specific contexts or roles, required to support practitioners. 


\section{Conflict of interest}

The authors declare they have no competing interests. Each author of this paper has completed the ICMJE conflict of interest statement.

\section{References}

1. American Academy of Orthopaedic Surgeons. Emergency care and transportation of the sick and injured. Jones \& Bartlett Learning; 1971.

2. EMS Chiefs of Canada. The future of EMS in Canada: Defining the new road ahead [Internet]. Calgary AB: Paramedic Chiefs of Canada, 2006, p.91. Available at: www. emscc.ca/docs/EMS-Strategy-Document.pdf [Accessed 2 May 2016].

3. Commission on the Future of Health Care in Canada, Romanow RJ. Commission on the Future of Health Care in Canada 2002, November 28.

4. Health Professions Regulatory Advisory Council. Regulation of paramedics and emergency medical attendants: a jurisdictional review. Toronto ON: Health Professions Regulatory Advisory Council, 2012.

5. Government of British Columbia. Emergency Health Services Act. Victoria BC: Queen's Printer, 1996. Available at: www.bclaws.ca/civix/document/id/complete/ statreg/96182_01

6. Legislative Assembly of New Brunswick. An Act Respecting the Paramedic Association of New Brunswick. Saint John NB: Legislative Assembly of New Brunswick, 2006. Available at: www.gnb.ca/legis/bill/editform-e. asp?ID=456\&legi $=55 \&$ num $=3$

7. Government of British Columbia. Emergency Medical Assistants Regulation. Victoria BC: Queen's Printer; 2010. Available at: www.bclaws.ca/civix/document/id//c/ statreg/210_2010

8. EMS Chiefs of Canada. The Canadian tactical paramedic training competency profile \& best practices. Calgary $A B$ : Paramedic Chiefs of Canada, 2008. Available at: www. emscc.ca/docs/TacticalParamedicProfile-May2008.pdf [Accessed 2 May 2016].

9. EMS Chiefs of Canada. The Canadian CBRNE paramedic training competency profile \& best practices. Calgary $\mathrm{AB}$ : Paramedic Chiefs of Canada, 2011.

10. Caffrey SM, Clark JR, Bourn S, et al. Paramedic specialization: a strategy for better out-of-hospital care. Air Med J 2014;33:265-73.

11. Feldman MJ, Lukins JL, Verbeek PR, MacDonald RD, Burgess RJ, Schwartz B. Half-a-million strong: the emergency medical services response to a single-day, mass-gathering event. Prehosp Disaster Med 2004;19:28796.

12. Acker JJ, Johnston TJ, Lazarsfeld-Jensen A, Acker J. Industrial paramedics, out on site but not out of mind. Rural
Remote Health 2014;14:2856. Available at: www.rrh.org.au/ publishedarticles/article_print_2856.pdf [Accessed 2 May 2016].

13. Campbell S, Petrie D, MacKinley R, et al. Procedural sedation and analgesia facilitator-expanded scope role for paramedics in the emergency department. Australasian Journal of Paramedicine 2015;6(3).

14. Campbell SG, Janes SE, MacKinley RP, et al. Patient management in the emergency department by advanced care paramedics. Healthc Manage Forum 2012;25;26-31.

15. Jensen JL, Travers AH, Bardua DJ, et al. Transport outcomes and dispatch determinants in a paramedic longterm care program: a pilot study. CJEM 2013:15;206-13.

16. DL Services. A survey of community paramedic programs in Ontario [Internet]. County of Renfrew Paramedic Service, 2013. 22 p. Available at: www.communityparamedic.ca/ media/download_gallery/Ontario\%20Community $\% 20$ Paramedic\%20Survey\%20Report\%20rev $\% 209 \% 20$ April\%202013\%20pdf\%20-\%20Adobe\%20Acrobat\%20Pro. pdf [Accessed 2 May 2016].

17. Mason S, Knowles E, Freeman J, Snooks H. Safety of paramedics with extended skills. Acad Emerg Med 2008;15:607-12.

18. Mason S, Knowles E, Colwell B, et al. Effectiveness of paramedic practitioners in attending 999 calls from elderly people in the community: cluster randomised controlled trial. BMJ 2007;335:919.

19. County of Renfrew. Aging at home [Internet]. Renfrew County, ON: no date. Available at: www. communityparamedic.ca/pages/home/aging-at-home.php [Accessed 2 May 2016].

20. Goldstein J, McVey J, Ackroyd-Stolarz S. The role of emergency medical services in geriatrics: bridging the gap between primary and acute care. CJEM 2016;18:54-61.

21. O'Meara P. Would a prehospital practitioner model improve patient care in rural Australia? Emerg Med J 2003;20:199203.

22. Toronto Paramedic Services. Community paramedicine [Internet]. Toronto ON, no date. Available at: http:// torontoparamedicservices.ca/special-units-teams/ community-paramedicine/ [Accessed 2 May 2016].

23. Bray JE, Coughlan K, Mosley I, Barger B, Bladin C. Are suspected stroke patients identified by paramedics transported to appropriate stroke centres in Victoria, Australia? Intern Med J 2014;44:515-8.

24. Cheskes $S$, Turner L, Foggett $R$, et al. Paramedic contact to balloon in less than 90 minutes: a successful strategy for ST-segment elevation myocardial infarction bypass to primary percutaneous coronary intervention in a Canadian emergency medical system. Prehosp Emerg Care 2011;:15:490-8.

25. Jensen JL, Walker M, Denike D, et al. Paramedic myocardial infarction care with fibrinolytics: a process map and hazard analysis. ibid. 2013;17:429-34. 


\section{References (continued)}

26. Le May MR, Davies RF, Dionne R, et al. Comparison of early mortality of paramedic-diagnosed ST-segment elevation myocardial infarction with immediate transport to a designated primary percutaneous coronary intervention center to that of similar patients transported to the nearest hospital. Am J Cardiol 2006;98:1329-33.

27. Sanossian N, Liebeskind DS, Eckstein M, et al. Routing ambulances to designated centers increases access to stroke center care and enrollment in prehospital research. Stroke 2015;46:2886-90.

28. BC Emergency Health Services. Trauma management [Internet]. Vancouver BC, 2014, updated 26 August 2015. Available at: https://bctg.bcas.ca/Condition/Principles/16 [Accessed 2 May 2016].

29. BC Emergency Health Services. Acute coronary syndrome (ACS) [Internet]. Vancouver BC, 2015, updated 26 August 2015. Available at: https://bctg.bcas.ca/Condition/ Principles/45 [Accessed 2 May 2016].

30. BC Emergency Health Services. Stroke [Internet]. Vancouver BC, 2015, updated 26 August 2015. Available at: https://bctg.bcas.ca/Condition/Principles/22 [Accessed 2 May 2016].

31. Nova Scotia Emergency Health Services. Chest pain [Internet]. Halifax NS, 2013. Available at: http://novascotia. ca/dhw/ehs/documents/CPG/EHS6228.02\%20Chest $\% 20$ Pain.pdf [Accessed 2 May 2016].

32. Nova Scotia Emergency Health Services. Stroke [Internet]. Halifax NS, 2013. Available at: http://novascotia.ca/dhw/ehs/ documents/CPG/EHS6288\%2005\%20Stroke.pdf [Accessed 2 May 2016].

33. Newton M, Tunn E, Moses I, Ratcliffe D, Mackway-Jones K. Clinical navigation for beginners: the clinical utility and safety of the Paramedic Pathfinder. Emerg Med J 2014;31(e1) e29-34.

34. Charmaz K. Constructing grounded theory. Sage Publications, Los Angeles, 2014.

35. Corbin J, Strauss A. Basics of qualitative research: techniques and procedures for developing grounded theory. Sage Publications, Los Angeles, 2014.

36. Creswell JW. Qualitative inquiry and research design: choosing among five approaches. Sage Publications, Los Angeles, 2013.

37. Woods D, Fassnacht C. Transana v2. 20. Computer software] http://transana.org Madison, Wl: The Board of Regents of the University of Wisconsin System, 2007.

38. O'Meara P, Ruest M, Martin A. Integrating a community paramedicine program. Australasian Journal of Paramedicine 2015;12:1-5

39. Jensen JL, Bigham BL, Blanchard IE, et al. The Canadian National EMS research agenda: a mixed methods consensus study. CJEM 2013;15:73-82.

40. O'Meara P, Ruest M, Stirling C. Community paramedics: the role of higher education as an enabling factor. Australasian Journal of Paramedicine 2014;11.

41. O'Meara P. Paramedics marching toward professionalism. J Emerg Prim Health Care 2009:7:1-5.

42. Johnston TM, Acker JJ. Paramedic professionalism and identity. Australasian Journal of Paramedicine 2016;13:1-7.

43. Trede F. Becoming professional in the 21st century. Australasian Journal of Paramedicine 2009;7(4).

44. Bigham BL, Kennedy SM, Drennan I, Morrison LJ. Expanding paramedic scope of practice in the community: a systematic review of the literature. Prehosp Emerg Care 2013;17:361-72.

45. DrL Services. A survey of community paramedic programs in Ontario. County of Renfrew Paramedic Services; 2013 Available at: www.communityparamedic.ca/pages/home/ resources.php

46. O'Meara P, Tourle V, Stirling C, Walker J, Pedler D. Extending the paramedic role in rural Australia: a story of flexibility and innovation. Rural Remote Health 2012;12:113.

47. Cooper S, Barrett B, Black S, et al. The emerging role of the emergency care practitioner. Emerg Med J 2004;21:614-8.

48. Martin-Misener R, Downe-Wamboldt B, Cain E, Girouard M. Cost effectiveness and outcomes of a nurse practitionerparamedic-family physician model of care: the Long and Brier Islands study. Prim Health Care Res Dev 2009;10:1425.

49. Paramedic Association of Canada. National occupational competence profile for paramedics in Canada. Ottawa ON, 2011. Available at: http://www.paramedic.ca/site/ nocp?nav=02 [Accessed 2 May 2016].

50. Frank JR, Snell L, Sherbino J. The draft CanMEDS 2015 physician competency framework-series IV. Ottawa: The Royal College of Physicians and Surgeons of Canada, 2014.

51. Canadian Physiotherapy Association. Essential competency profile for physiotherapists in Canada, 2012. Available at: http://npag.ca/PDFs/Joint\%20Initiatives/PTA\%20profile\%20 2012\%20English.pdf [Accessed 21 April 2016].

52. Frank JR, Danoff $D$. The CanMEDS initiative: implementing an outcomes-based framework of physician competencies. Med Teach 2007;29:642-7. 